a Dataset \#1: TNF (GSE64233): Replicate comparison

\section{Original data}

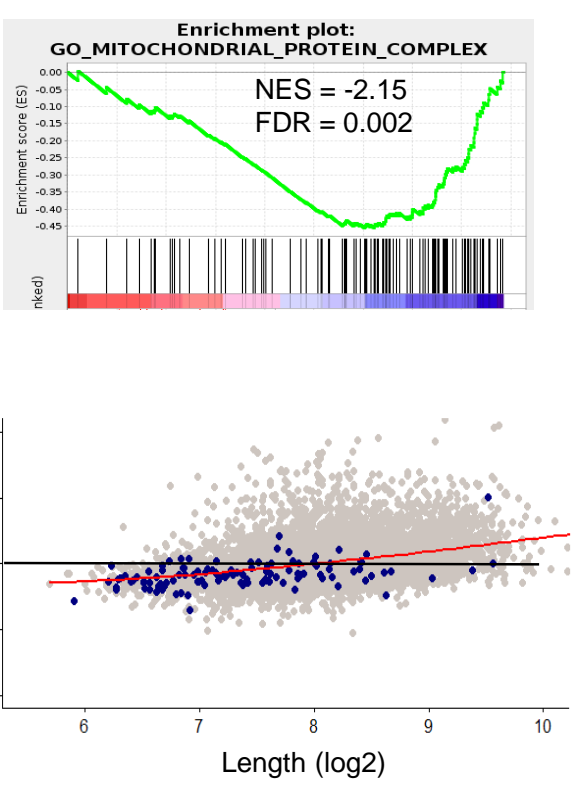

cqn normalization
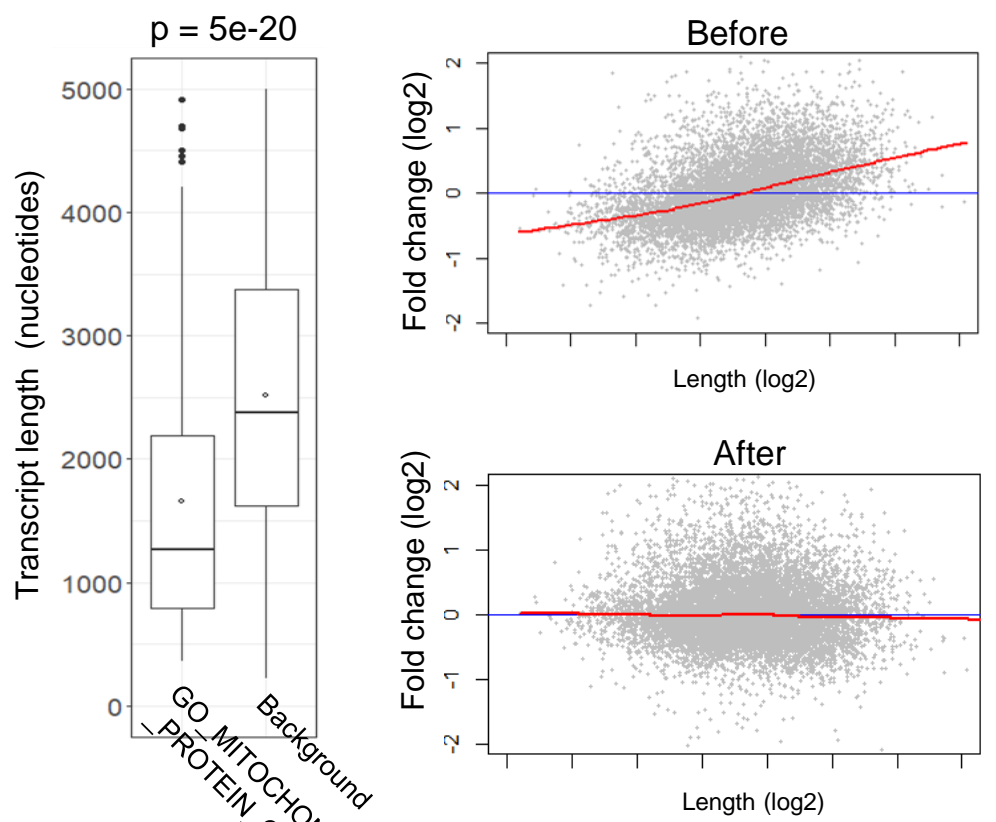

Corrected data

Enrichment plot:
GO_MITOCHONDRIAL_PROTEIN_COMPLEX
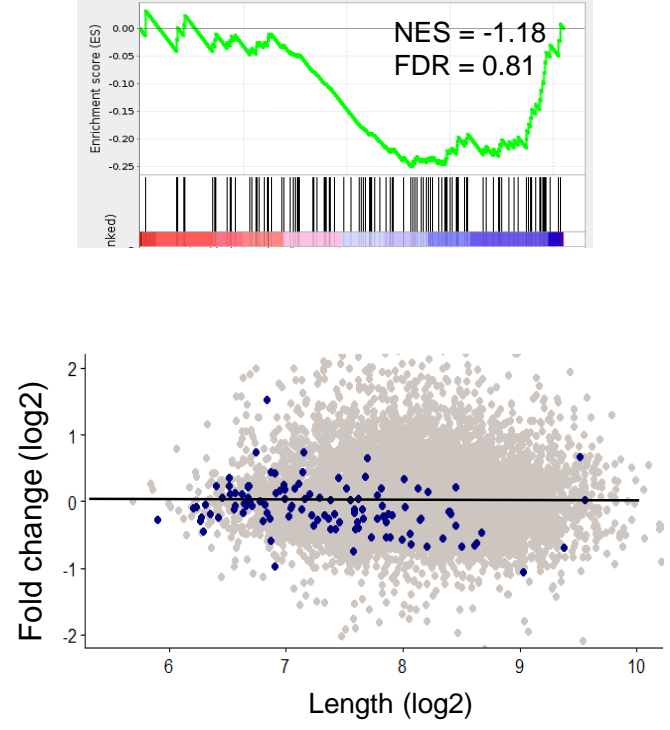

Supplementary Figure 3 
b Dataset \#1: TNF (GSE64233): Replicate comparison

Original data
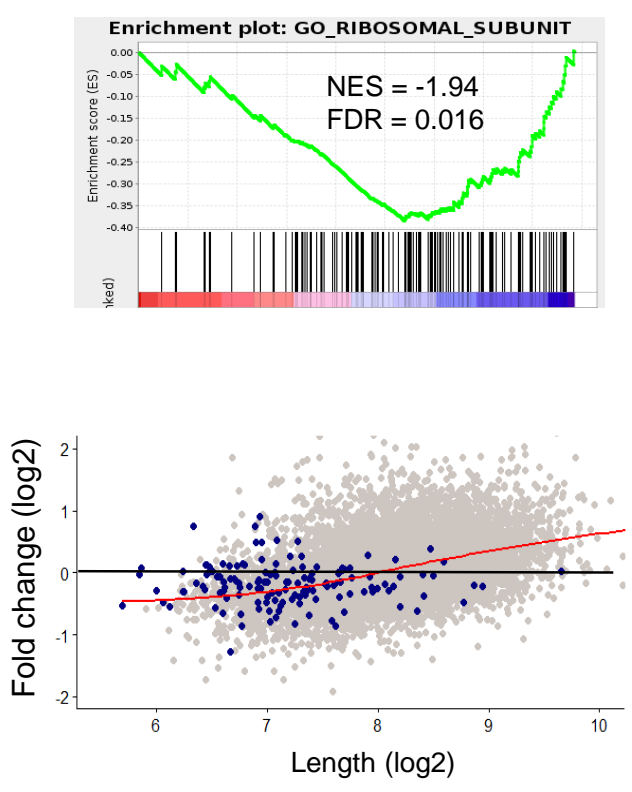

cqn normalization

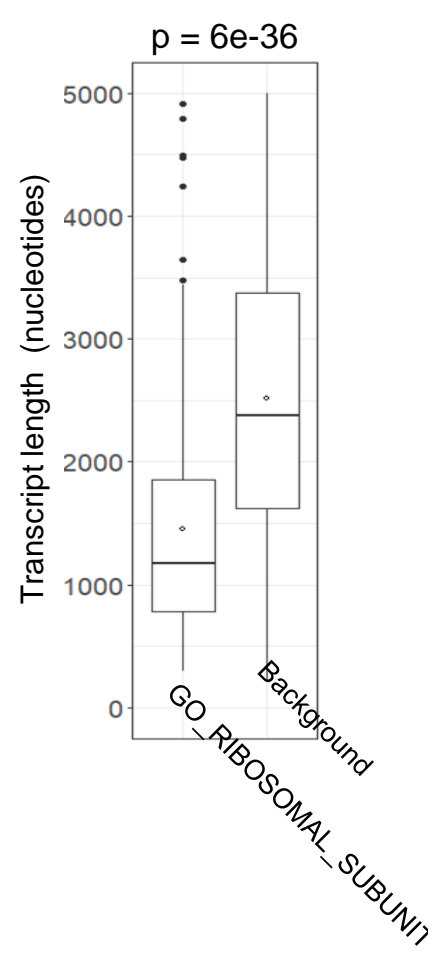

Corrected data
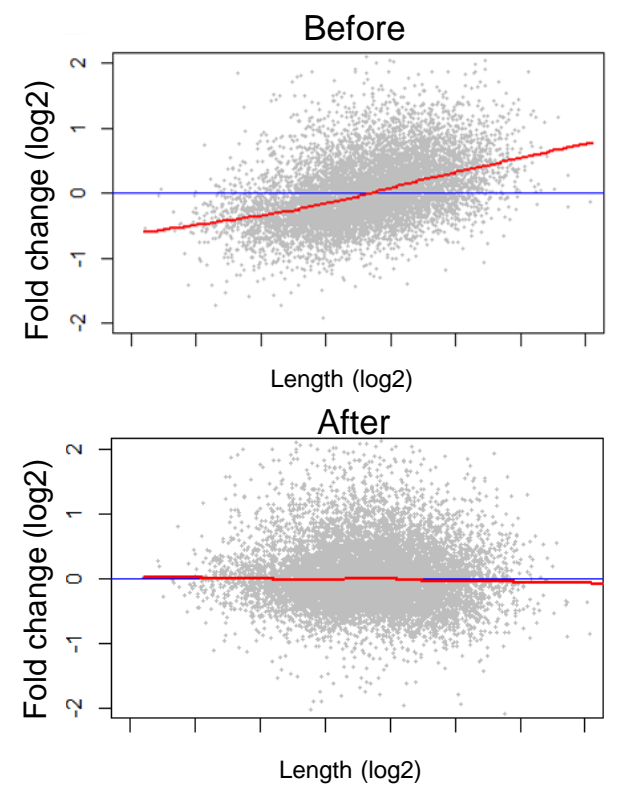

Enrichment plot: GO_RIBOSOMAL_SUBUNIT
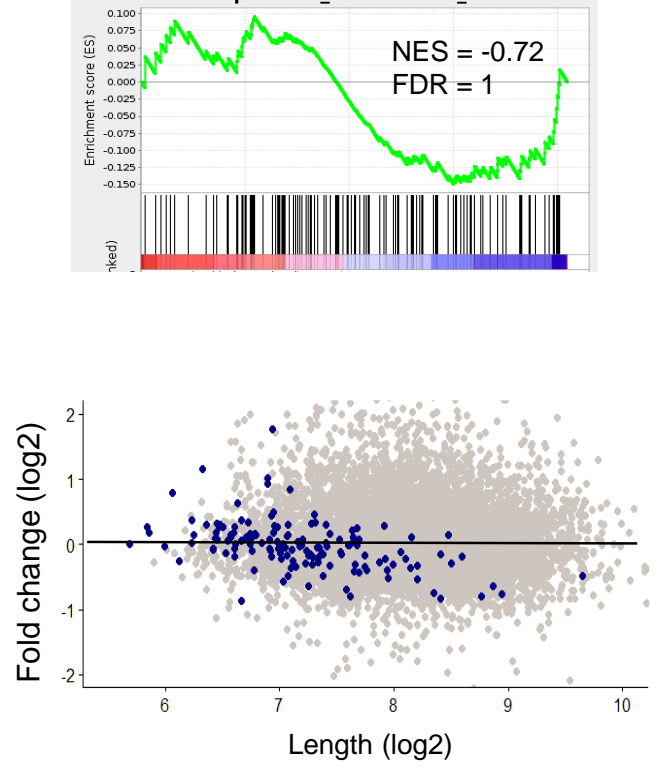

Supplementary Figure 3 
C Dataset \#1: TNF (GSE64233): Replicate comparison

Original data

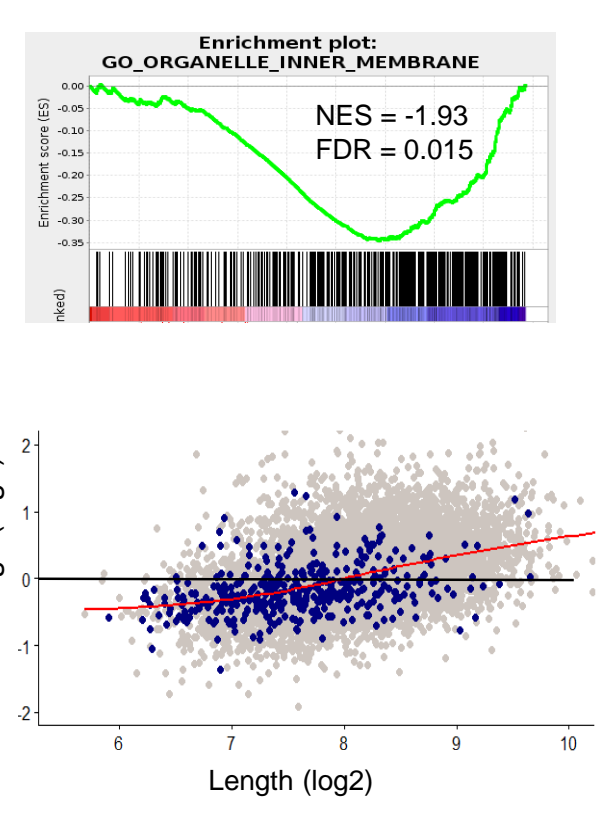

cqn normalization

Before

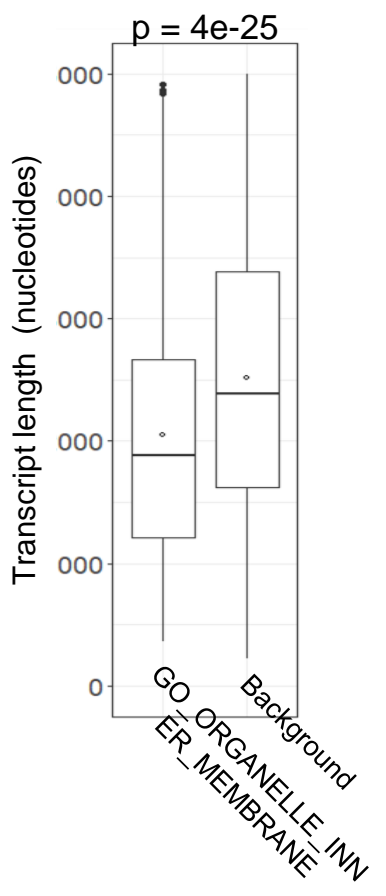

After
Corrected data
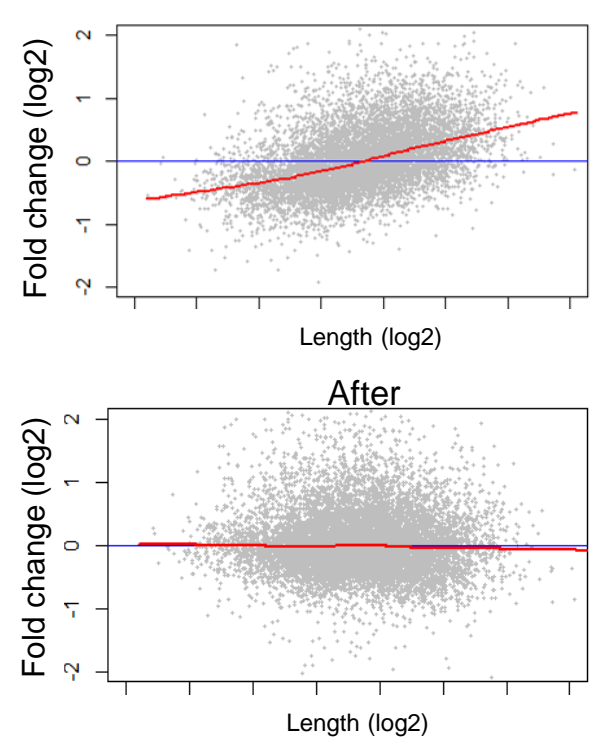

Enrichment plot:
GO_ORGANELLE_INNER_MEMBRANE
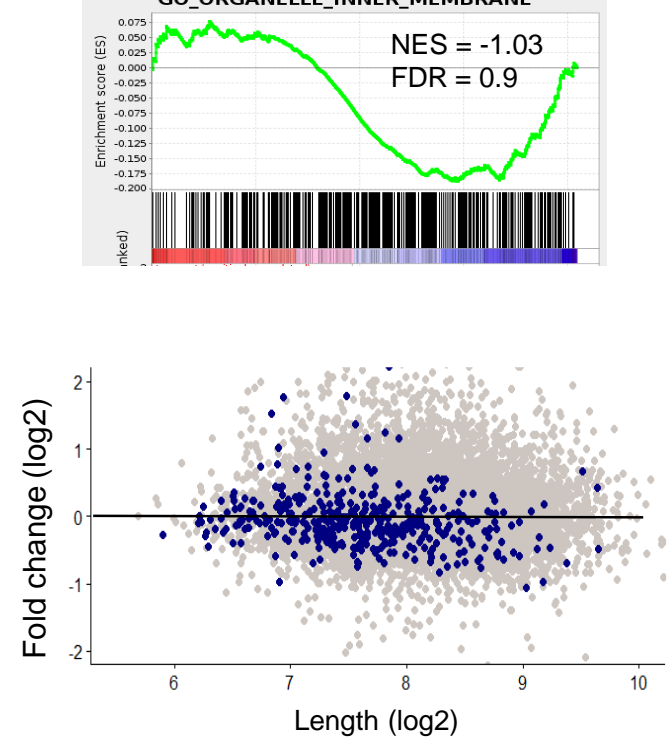

Supplementary Figure 3 
d Dataset \#10: shSRC-1 in BC cells (GSE99647): Replicate comparison

Original data
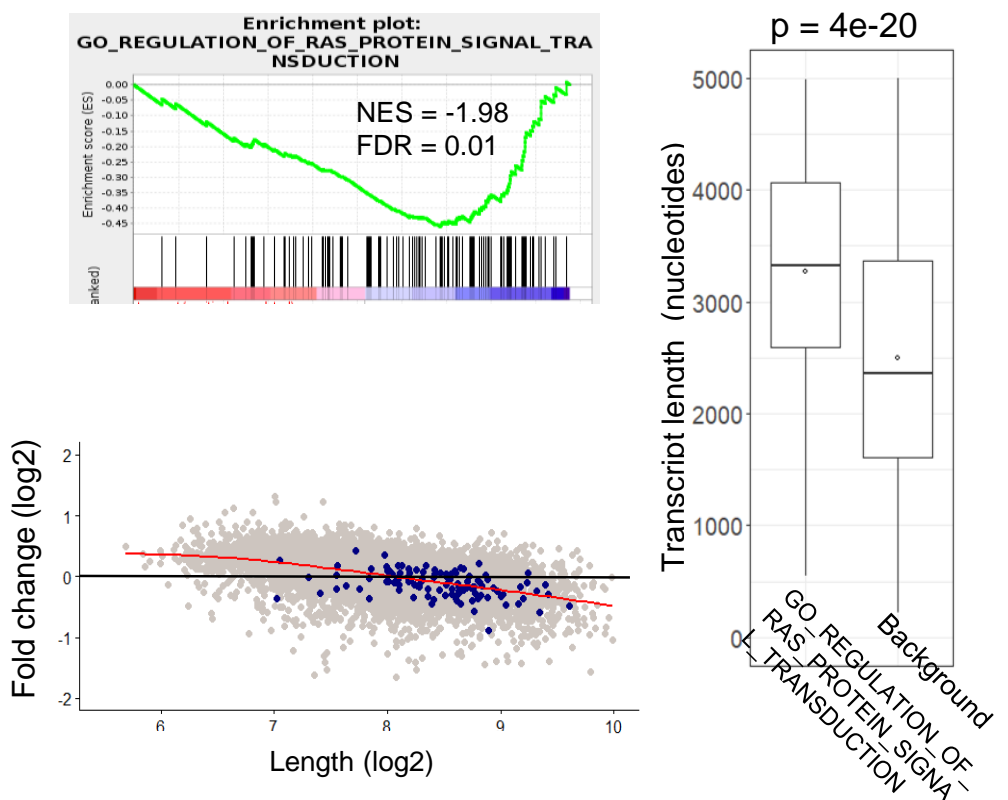

cqn normalization
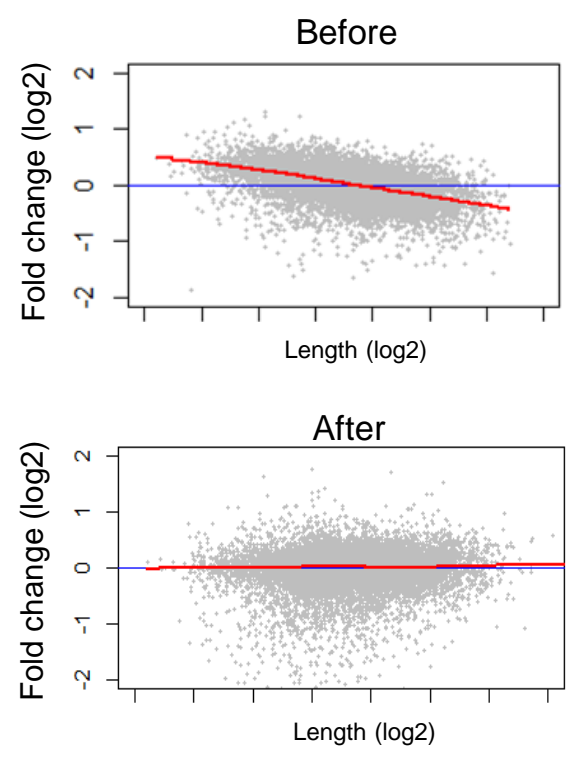

Corrected data

Enrichment plot:
GO_REGULATION_OF_RAS_PROTEIN_SIGNAL_TRA
NSDUCTIION
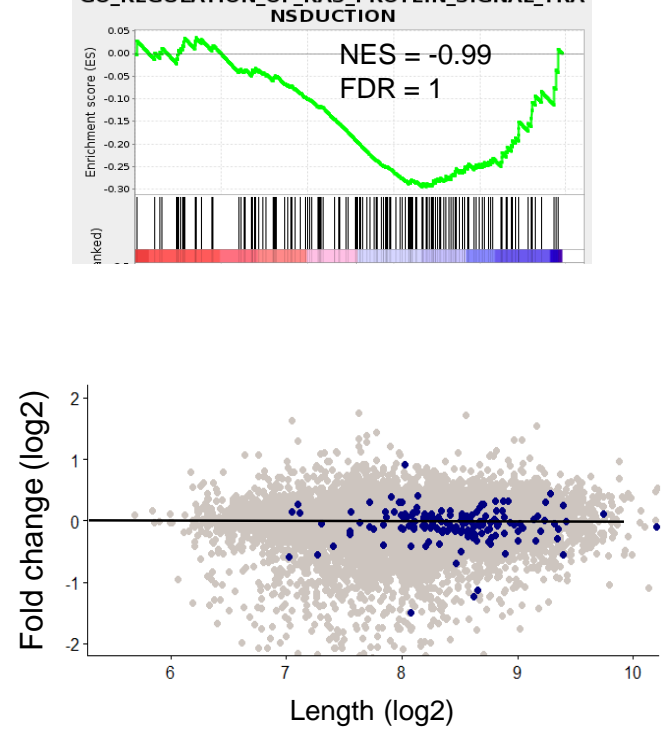
e Dataset \#10: shSRC-1 in BC cells (GSE99647): Replicate comparison

\section{Original data}
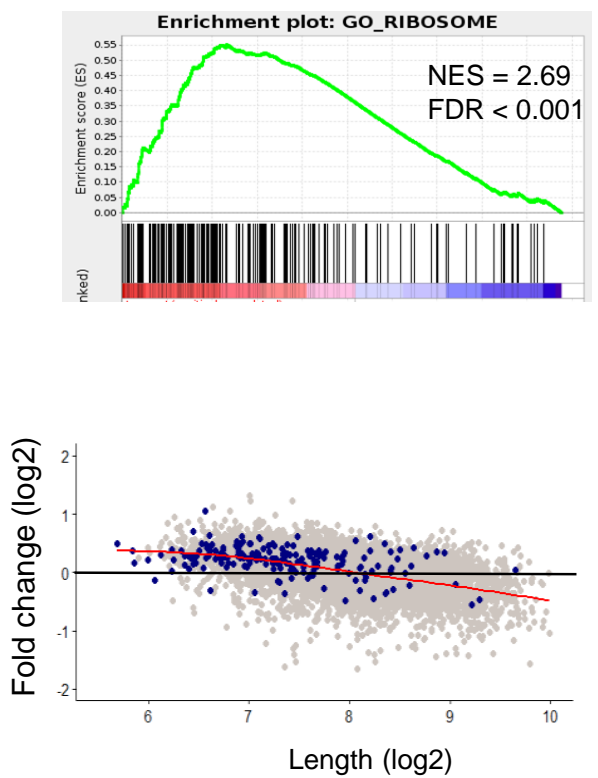

cqn normalization

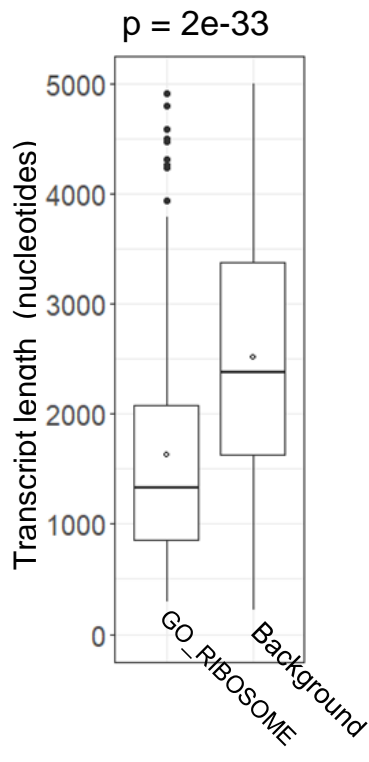

Corrected data
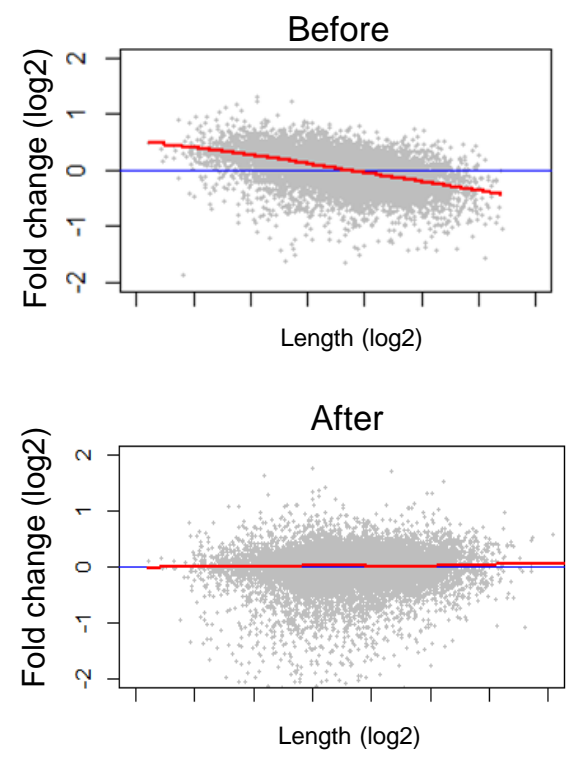

Enrichment plot: GO_RIBOSOME
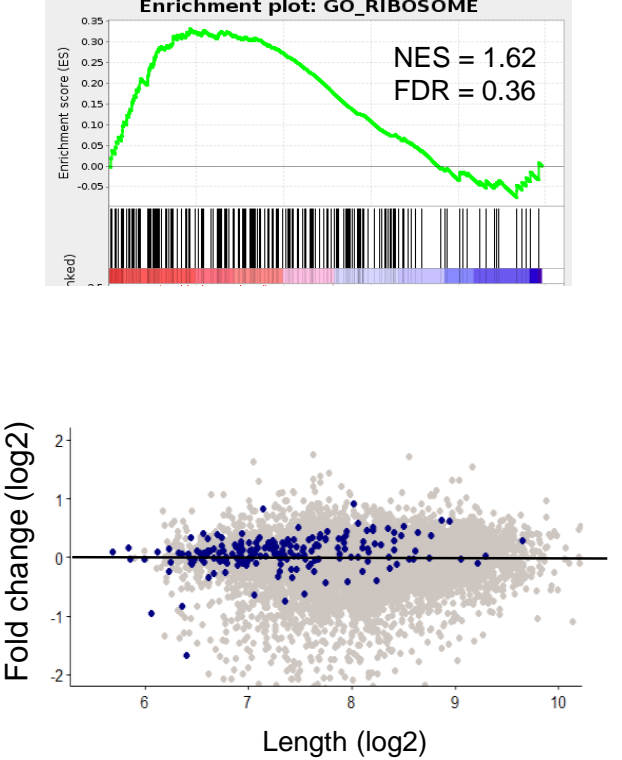


\section{Original data}
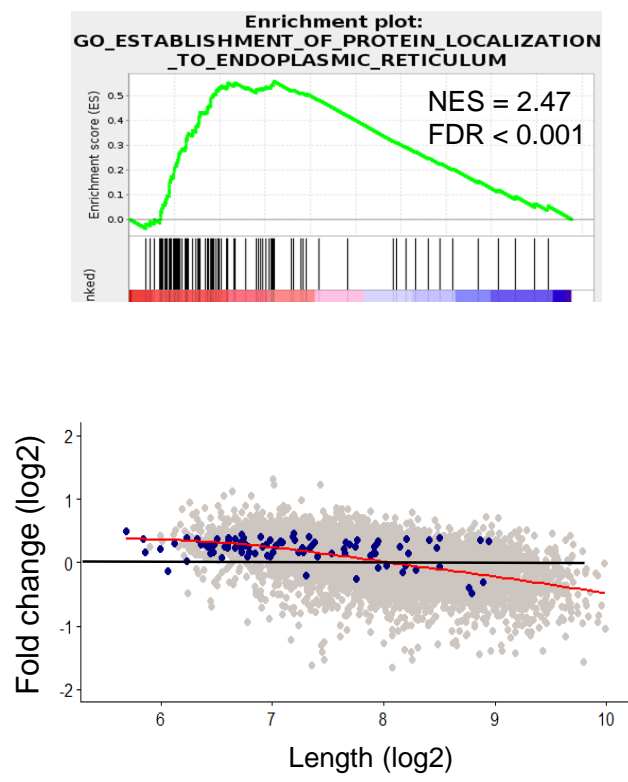

cqn normalization

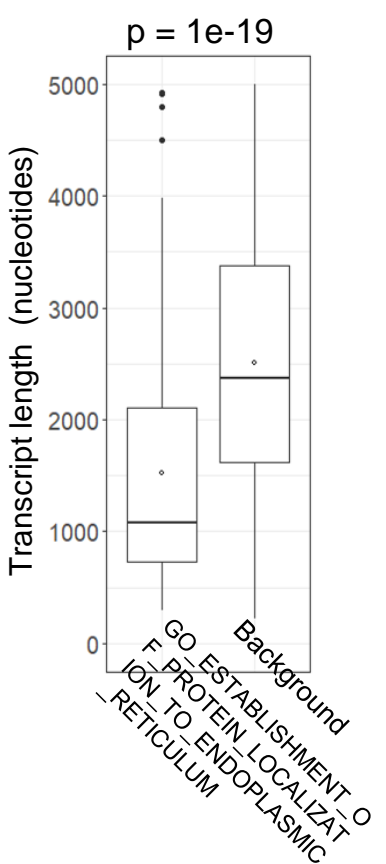

\section{Corrected data}
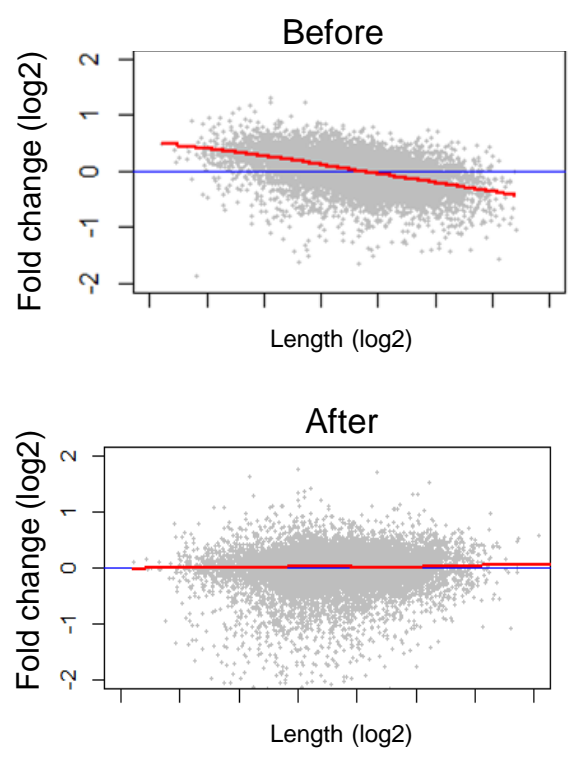

Enrichment plot:
GO ESTABLISHMENT OF PROTEIN LOCALIZATION GO_ESTABLISHMENT_OF_PROTEIN_LOCAL
-TO_ENDOPLASMIIC_RETICULUM
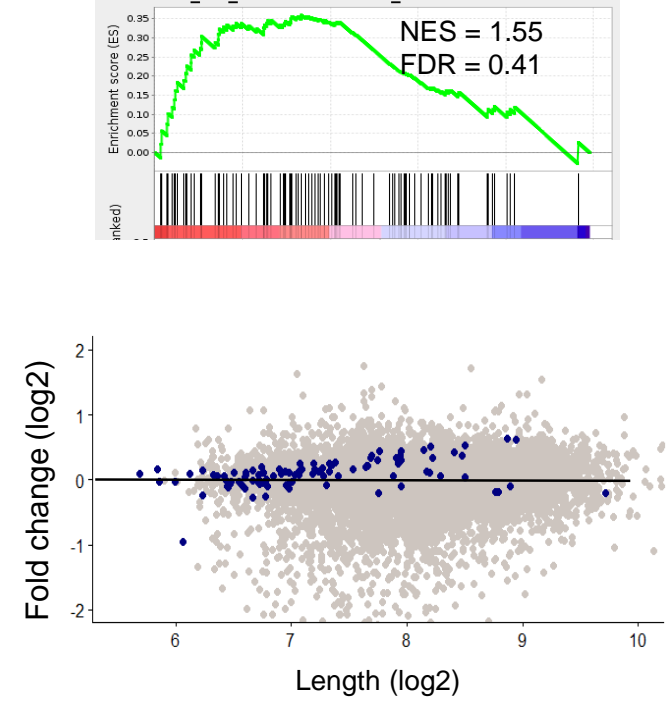

Supplementary Figure 3 
9 Dataset \#10: shSRC-1 in BC cells (GSE99647): Replicate comparison

Original data
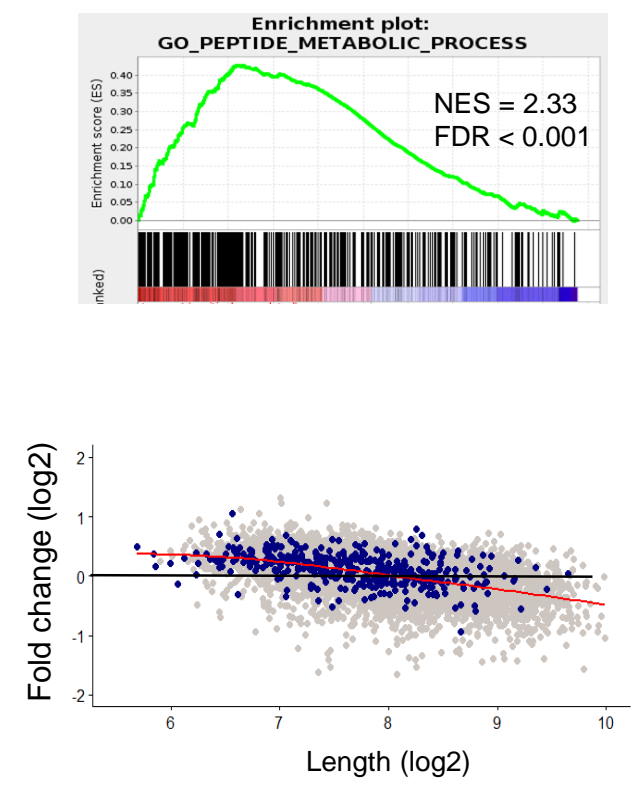

cqn normalization

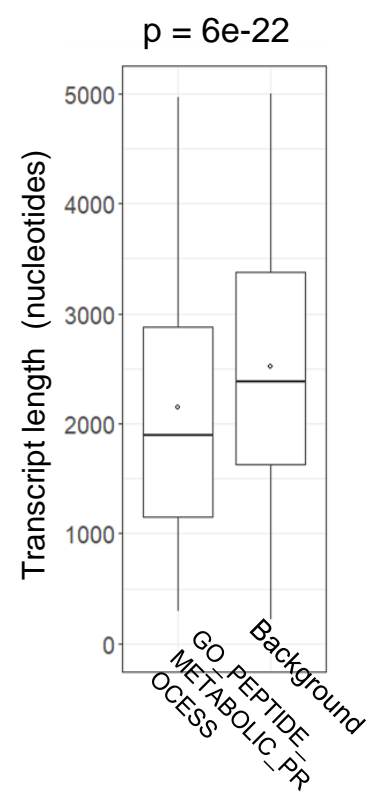

Corrected data
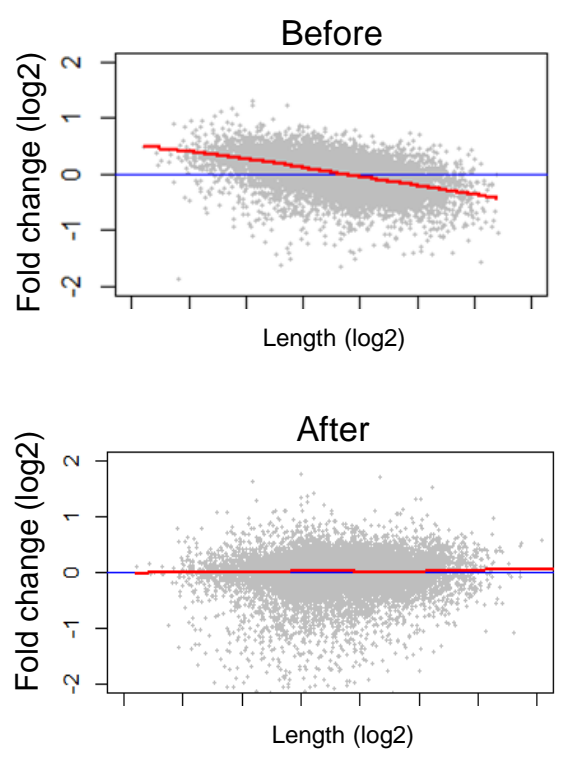

Enrichment plot:
GO_PEPTIDE_METABOLIC_PROCESS
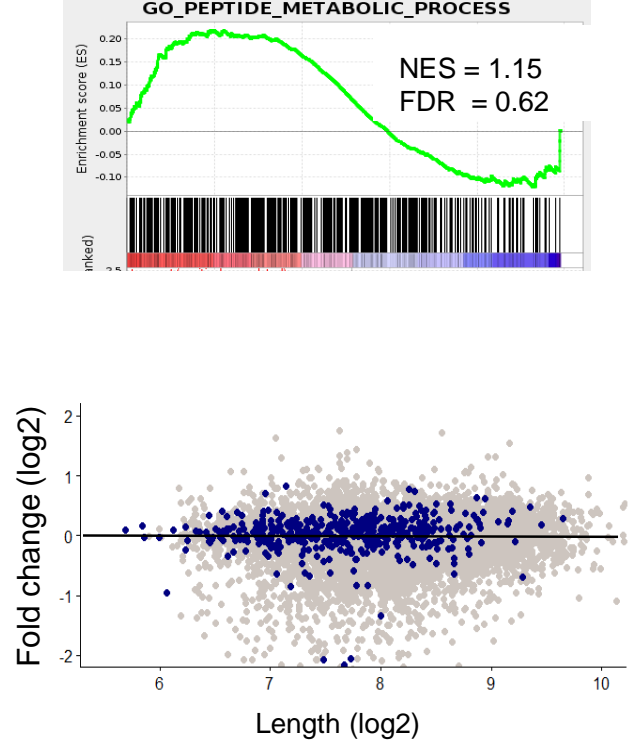

Supplementary Figure 3 
h Dataset \#8: NCS treated vs. untreated MCF-7 cells (GSE101738): Replicate comparison

Original data

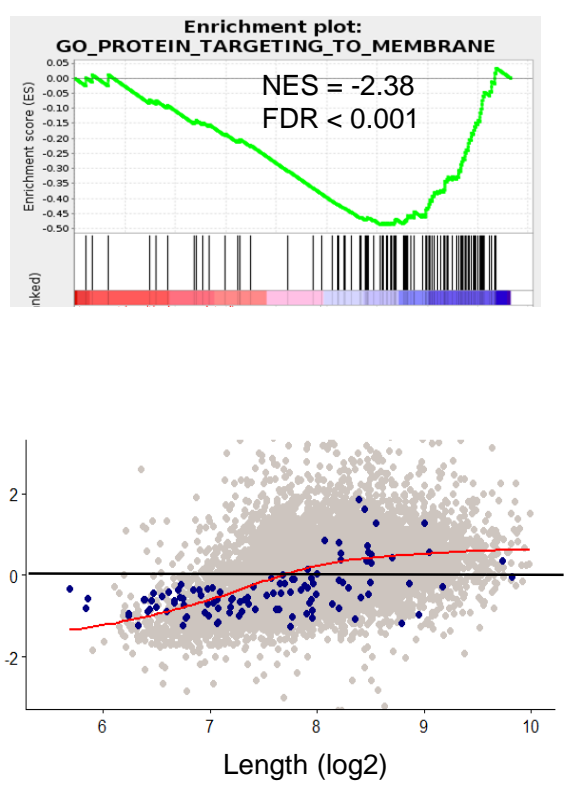

cqn normalization

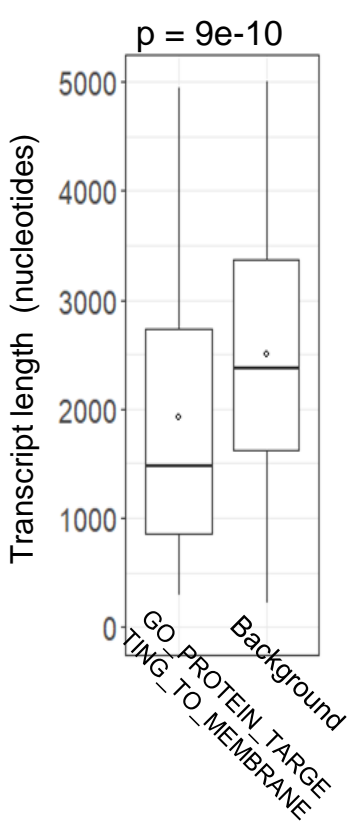

\section{Corrected data}
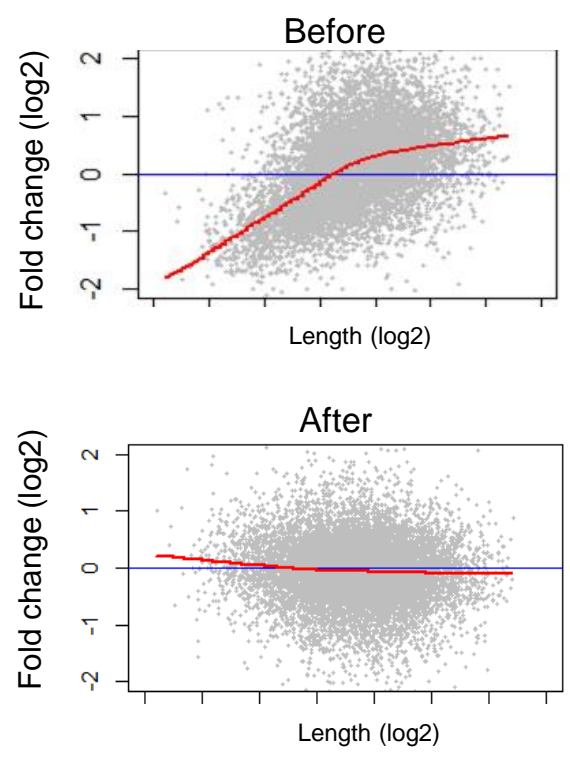

Enrichment plot:
GO_PROTEIN_TARGETING_TO_MEMBRANE
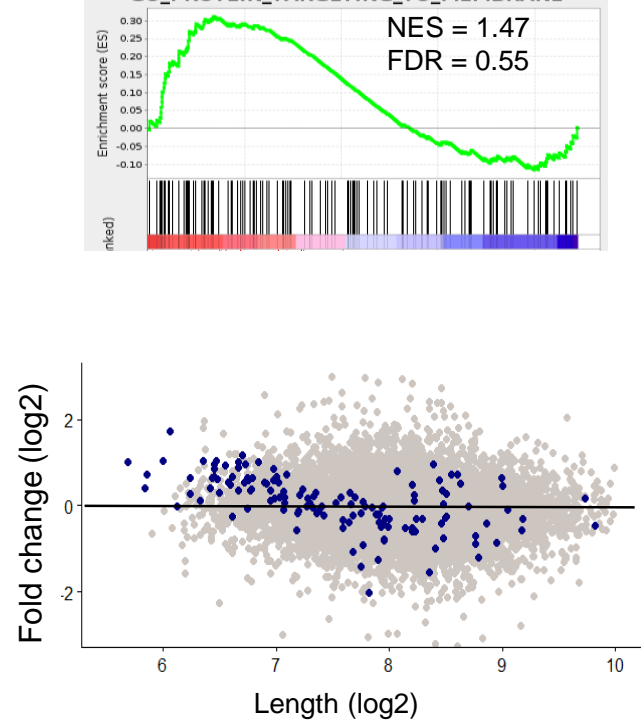

Supplementary Figure 3 
Dataset \#8: NCS treated vs. untreated MCF-7 cells (GSE101738): Replicate comparison

Original data
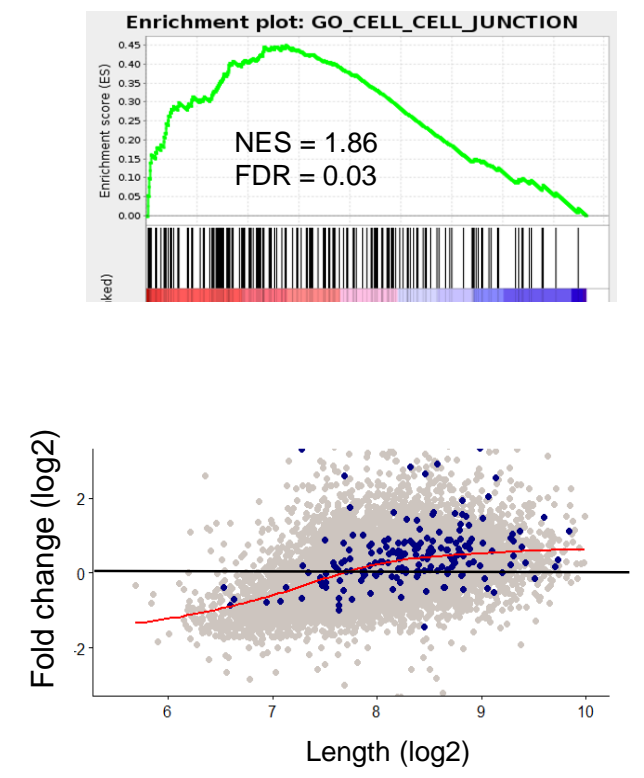

cqn normalization

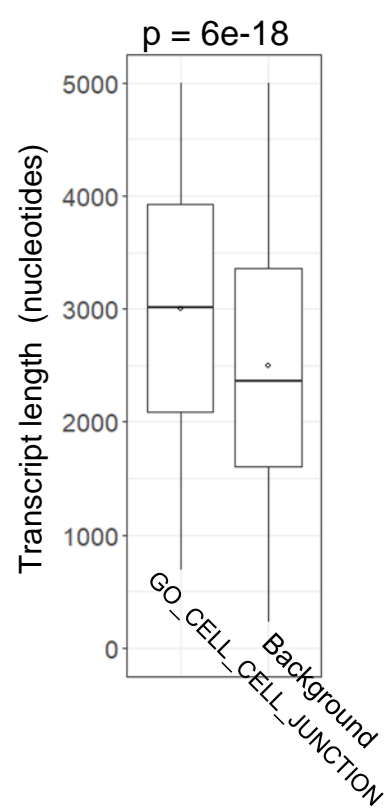

\section{Corrected data}
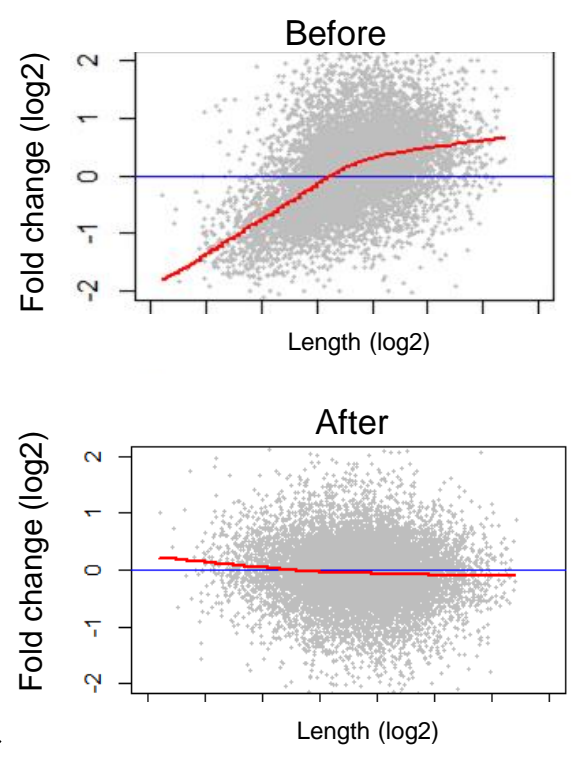
$\mathrm{FDR}=0.77$
Enrichment plot: GO_CELL_CELL_JUNCTION So 0.20 .20

$\mathrm{NES}=1.03$
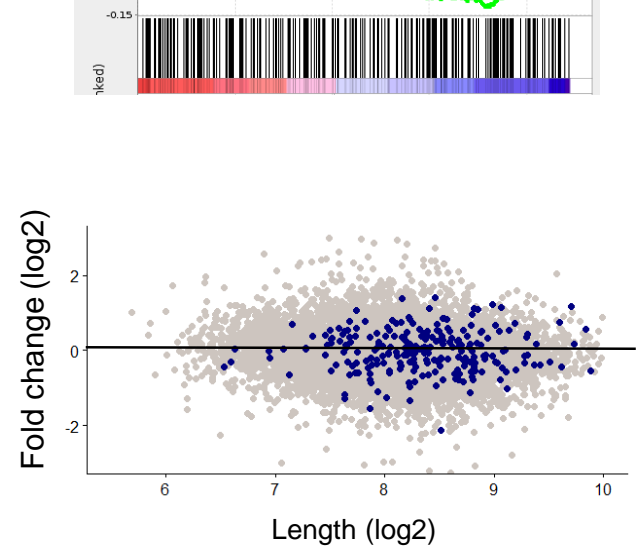
j Dataset \#8: NCS treated vs. untreated MCF-7 cells (GSE101738): Replicate comparison

Original data

Enrichment plot: GO_CYTOSOLIC_RIBOSOME
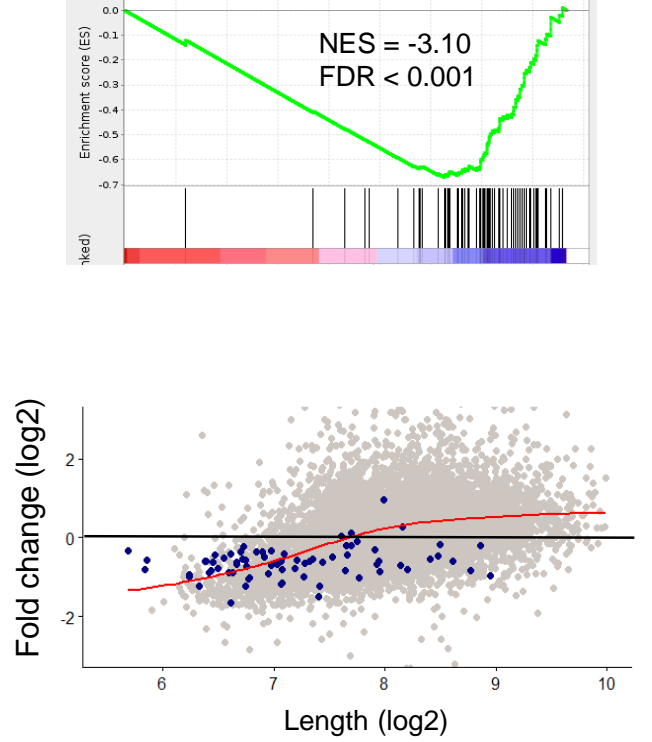

cqn normalization

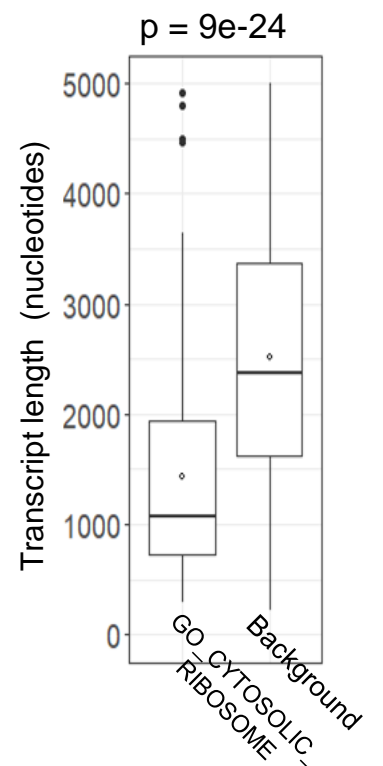

\section{Corrected data}
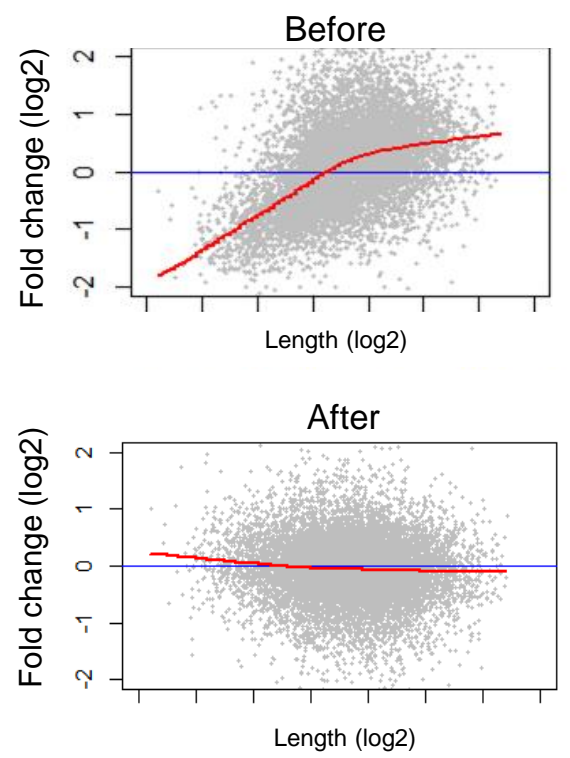

Enrichment plot: GO_CYTOSOLIC RIBOSOME
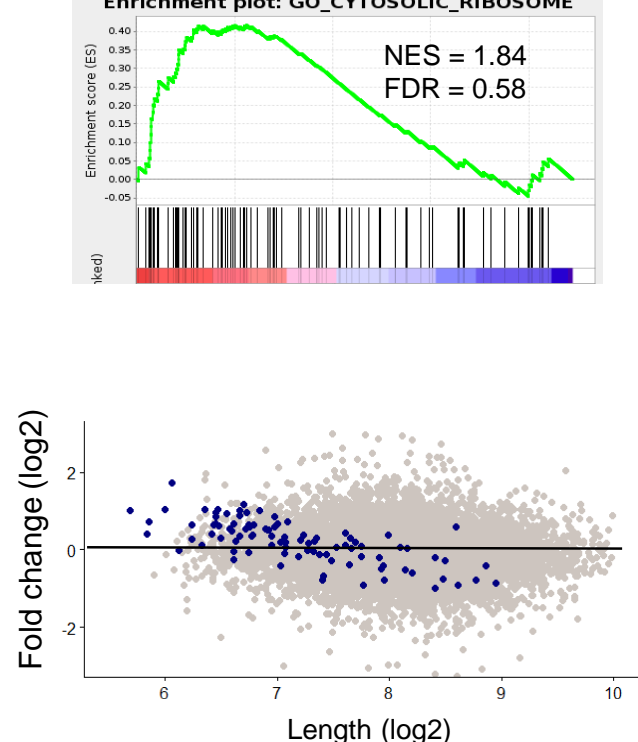

Supplementary Figure 3 
k Dataset \#8: NCS treated vs. untreated MCF-7 cells (GSE101738): Replicate comparison

\section{Original data}

Enrichment plot:
GO_ESTABLISHMENT_OF_PROTEIN_LCALIZATION
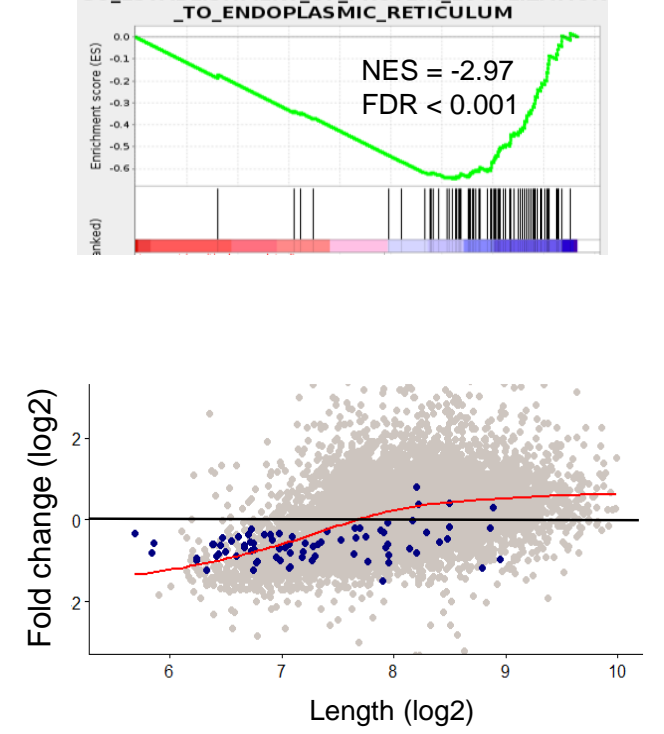

cqn normalization

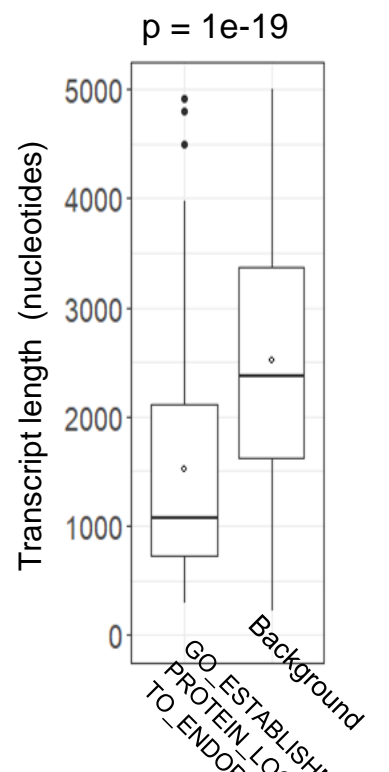

\section{Corrected data}
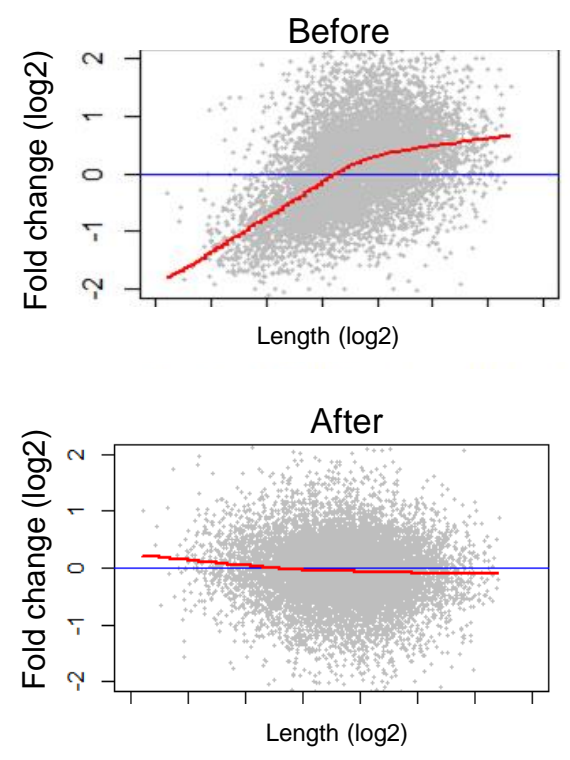

Enrichment plot:
GO_ESTABLISHMENT OF PROTEIN LOCALIZATION GO_ESTABLISHMENT_OF_PROTEIN_LOCA IZ
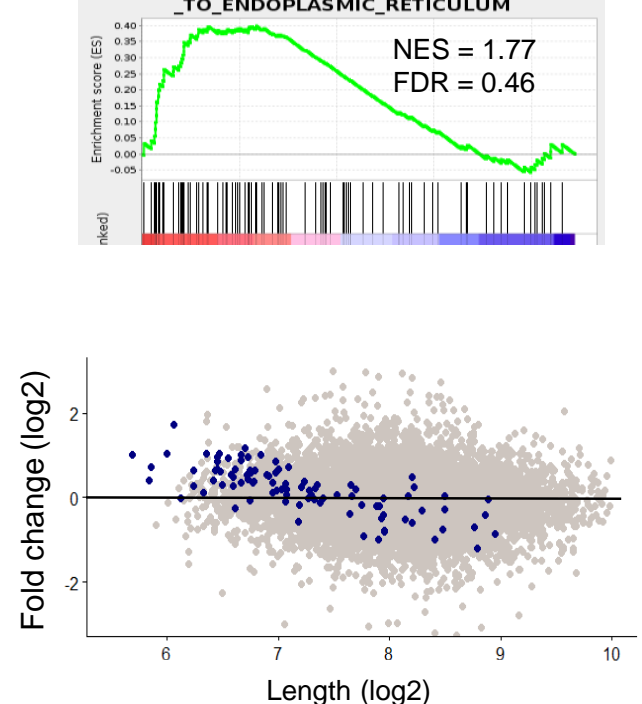

Supplementary Figure 3 
Original data
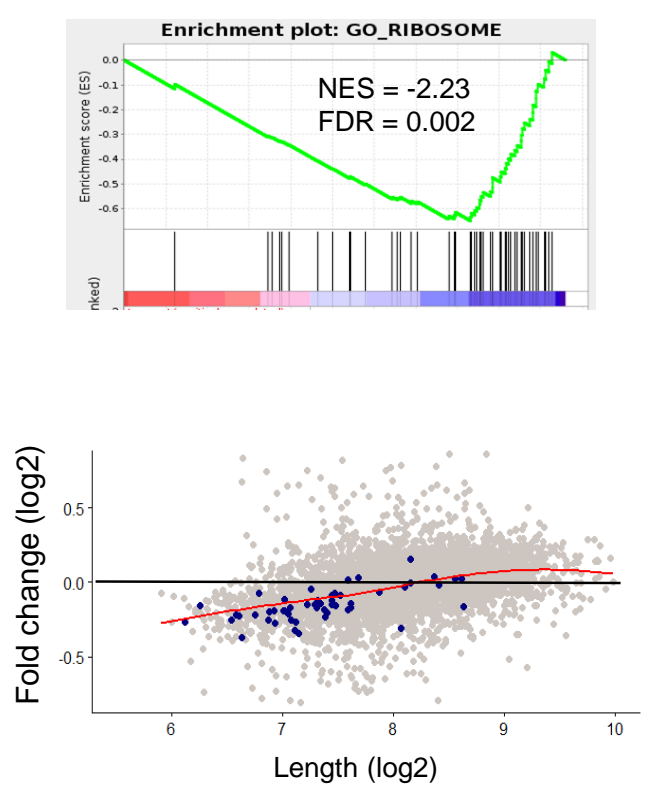

cqn normalization

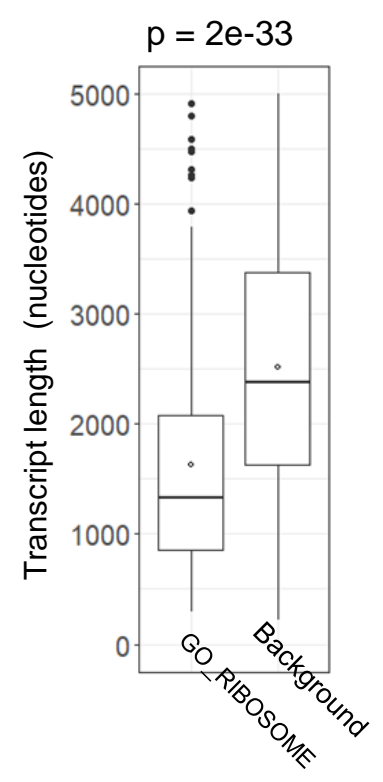

\section{Corrected data}
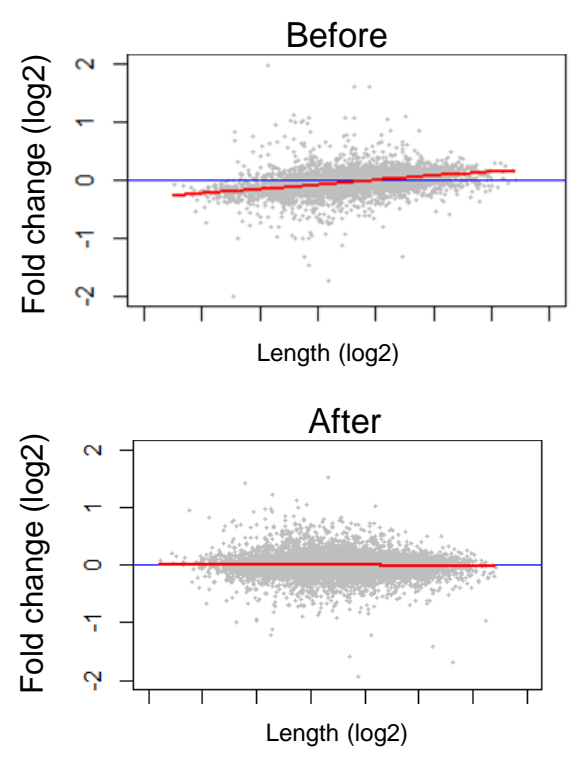

Enrichment plot: GO_RIBOSOME
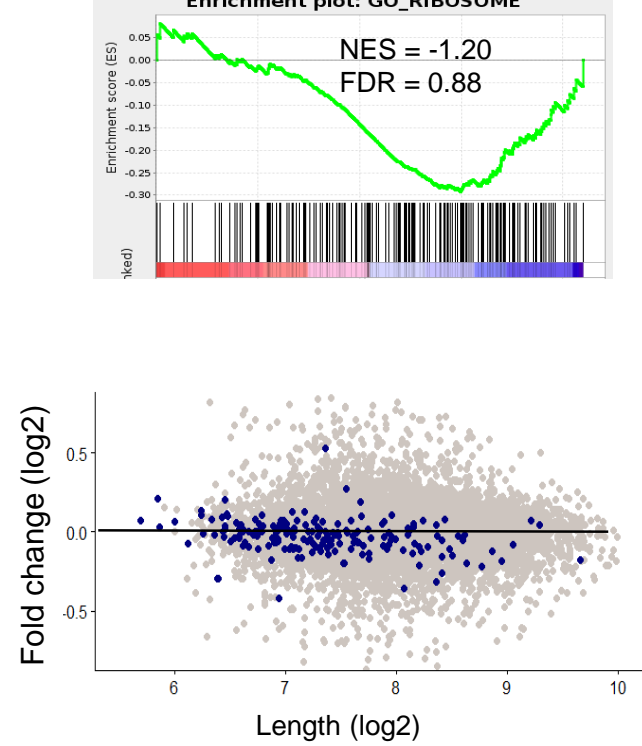

Supplementary Figure 3 
m Dataset \#18: Al-10-49 treatment on ME-1 cells (GSE101788): Replicate comparison

Original data

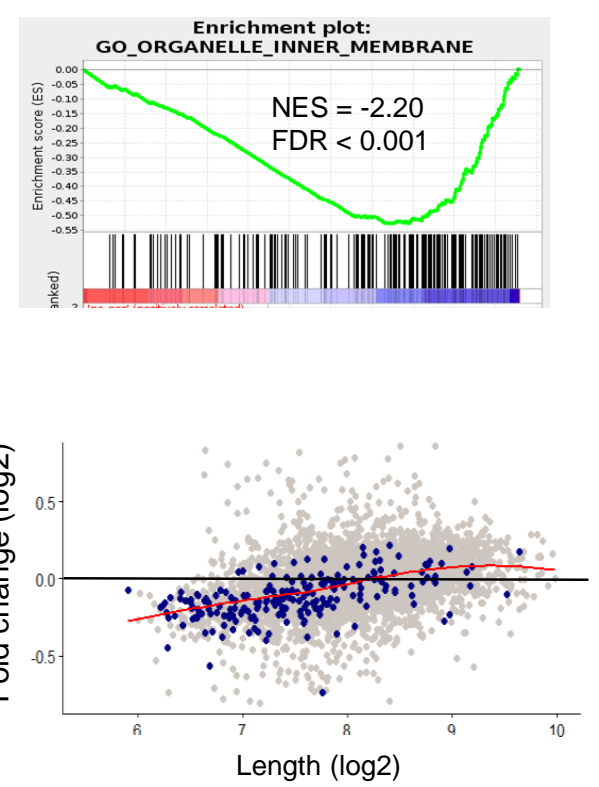

cqn normalization

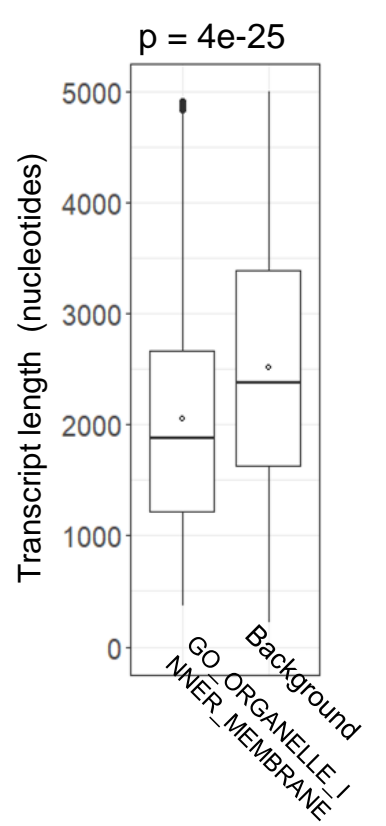

Corrected data
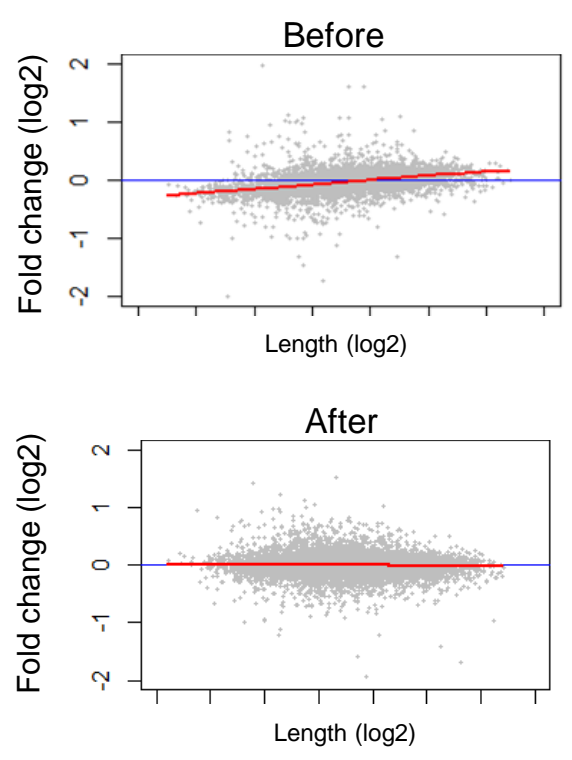

Enrichment plot:
GO_ORGANELLE_INNER_MEMBRANE
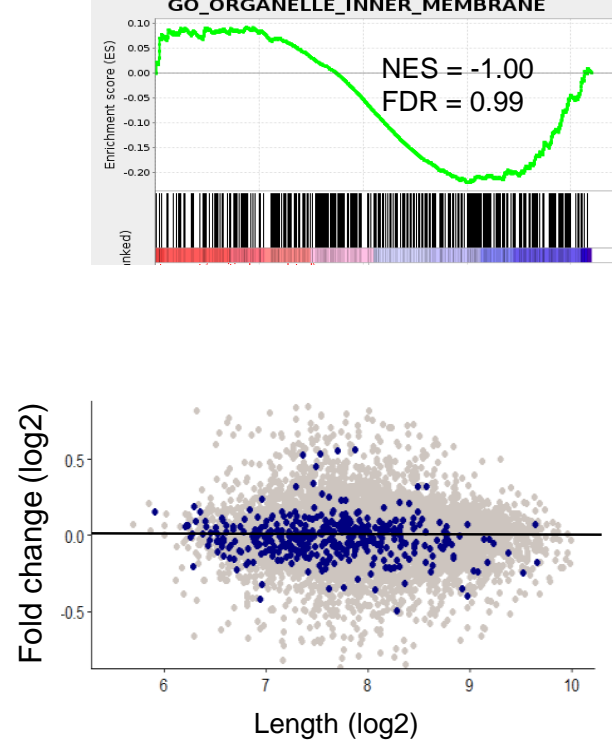

Supplementary Figure 3 
n Dataset \#18: Al-10-49 treatment on ME-1 cells (GSE101788): Replicate comparison

Original data

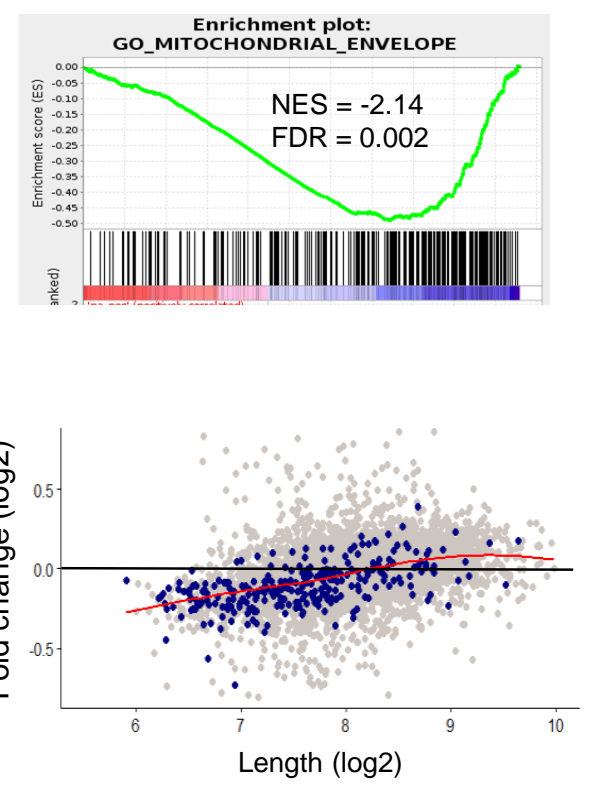

cqn normalization

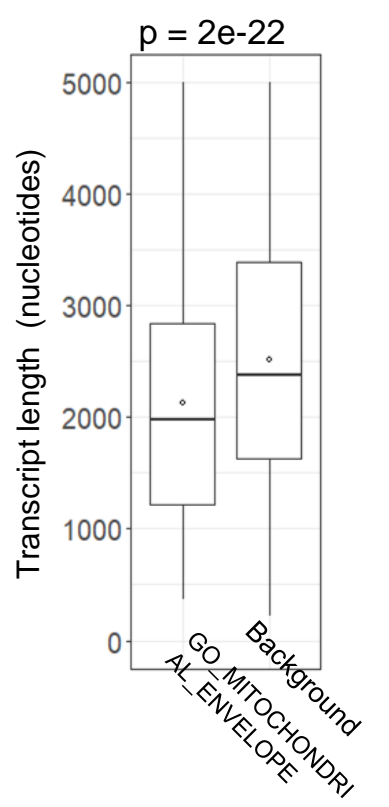

Corrected data
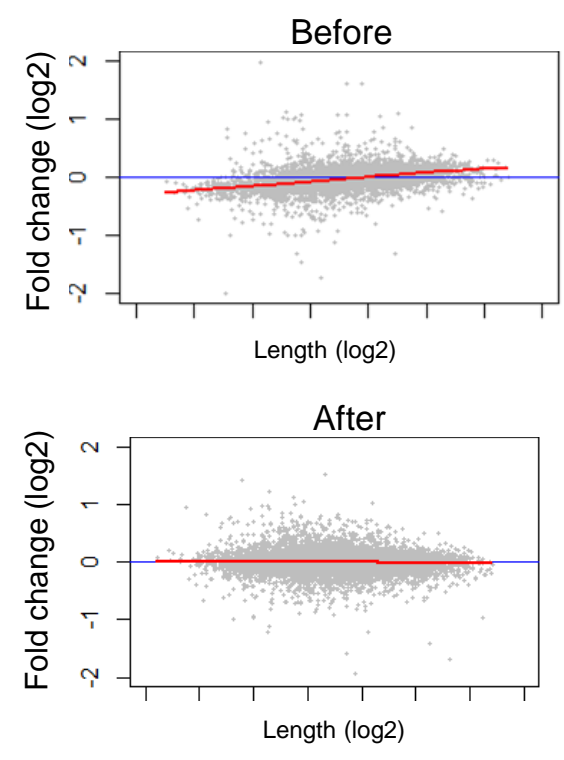

Enrichment plot:
TOCHONDRIAL_ENVELOPE
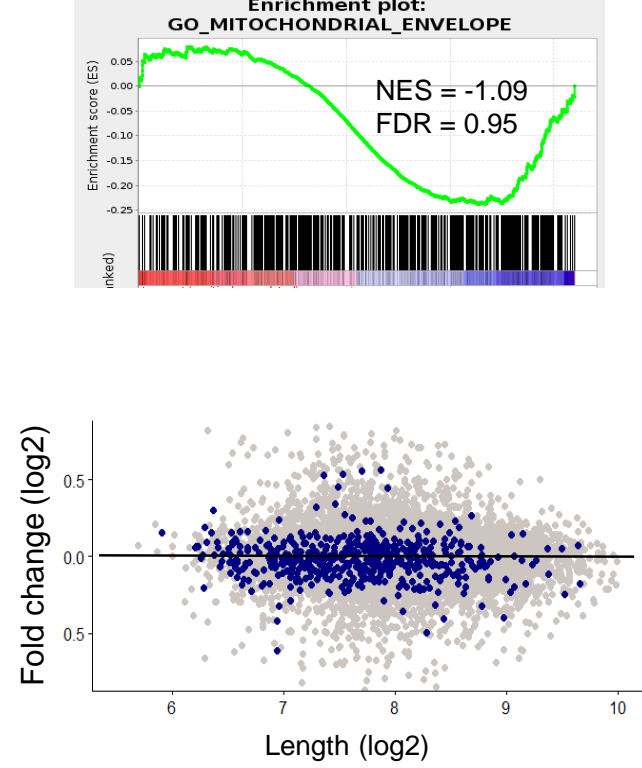

Supplementary Figure 3 